\title{
Review of Reconfigurable Microstrip Patch antenna for Wireless Application
}

\author{
Shraddha Pandey \\ MTech scholar \\ Department of Electronics and Communication \\ SISTec, Bhopal (M.P.)
}

\author{
Prof. Pankaj Vyas \\ Associate Professor \\ Department of Electronics and Communication \\ SISTec, Bhopal (M.P.)
}

\begin{abstract}
In recent time, world have seen a rapid growth in wireless communication. Development in antenna from single band to dual band and multi band had made the antenna system more compact. A frequency reconfigurable microstrip antenna using a PIN diode for multiband operation is using many application and hot research area. In this paper, reconfigurable microstrip patch antennas and their types like frequency, polarization, radiation pattern and gain are described.
\end{abstract}

Keywords- Microstrip Antenna, Reconfigurable, Frequency, Polarization, Radiation Pattern, Gain.

$* * * * *$

\section{INTRODUCTION}

Today we need reconfigurable, large bandwidth, and wideband antennas to satisfy the increasing demands for wireless communication applications. Reconfigurable antenna technique provides the capability to alter radiation pattern, polarization, operating frequency and combination of these two or more parameters in an antenna, which is not possible with conventional antennas. For modern wireless applications reconfigurability has become an important feature. By reconfiguring the antenna we can extensively reduce the hardware complexity, size and cost of communication systems. Multiband operation can be achieved by altering the current paths on antenna. Current paths can be altered by changing the states of PIN diodes or MEMS switches. Varactor diodes used as switches on slotted antenna to get the reconfigurability function for multi-standard personal communication systems. Reconfigurable slotted patch antenna presented for L-band frequency region, where the operating frequency varies as the angle of orientation of the slotted section varies but this design has limited multiband operation. Reconfigurable microstrip patch antennas are widely used in the current wireless communication systems due to their planar structure, low profile, low cost, lightweight, and the ease of fabrication. Switches are placed in the structure to change the radiator shape, by which the radiation from the patch is controlled, and hence, reconfigurability is achieved. Many modern communication system applications require different frequency bands with different polarization characteristics. Multifunction antennas have received a lot of attention in recent times because these antennas can provide multiple services and cover various frequency bands with different radiation characteristics. However, the use of carrier aggregation (CA) has been proposed in modern wireless systems such as LTE and $5 \mathrm{G}$.

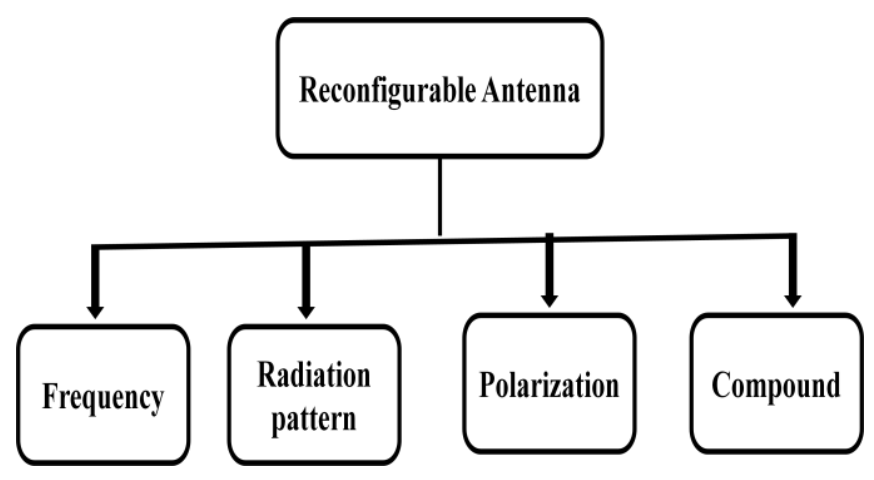

Figure 1: Types of Reconfigurable Antennas

\section{LITERATURE SURVEY}

B. Ijaz et al.,[1] A dual-band frequency reconfigurable monopole antenna is exhibited in this work. Reconfiguration of frequency bands is accomplished utilizing RF PIN diodes. An officially distributed antenna configuration is utilized as a beginning stage and is then changed to accomplish frequency reconfiguration instrument by consolidating RF PIN diodes. The antenna reverberates at focus frequency of $2.4 \mathrm{GHz}$ and 4.25 GHz when RF PIN diodes are turned OFF. Be that as it may, RF PIN diodes ON state brought about 1.84 and 3.66 $\mathrm{GHz}$ frequency bands. The 1.84 and $2.45 \mathrm{GHz}$ bands are constrained by modifying the electrical length of transformed L-formed resonator. While, $\mathrm{C}$-formed radiator is utilized to resound the proposed antenna at $3.66 \mathrm{GHz}$ and $4.56 \mathrm{GHz}$ frequency bands. In general, the recreation and estimation results demonstrated a decent understanding.

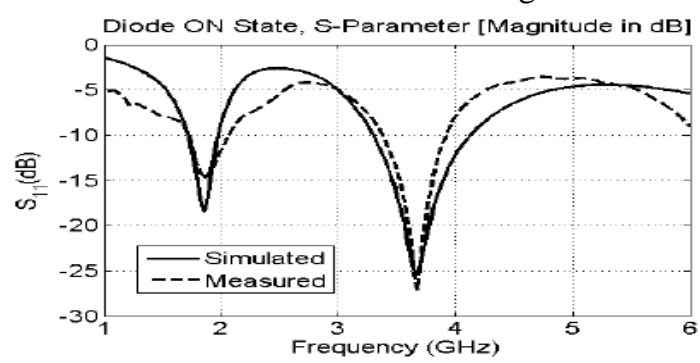

Figure 2: Simulated and measured magnitude of S11 at ON state [1] 


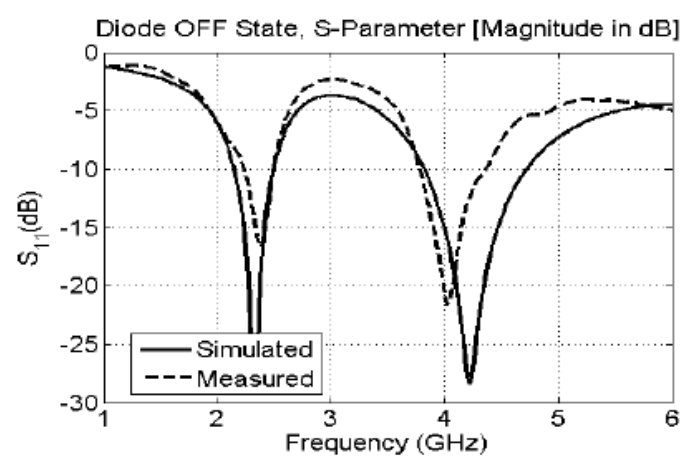

Figure 3: Simulated and measured magnitude of S11 at OFF state [1]

Figure 2 and figure 3 is showing result of proposed work and presenting detailed result in [1]

S. Kumar et al.,[2] In this article, a roundabout microstrip tunable wideband frequency and polarization reconfigurable antenna are researched. The wideband tunability is accomplished by setting the four varactor diodes between roundabout microstrip fix and roundabout ring. The impedance bandwidth of $2.09-2.96 \mathrm{GHz}(34.52 \%)$ is acknowledged by tuning the capacitance esteem from $4.15 \mathrm{pF}(0 \mathrm{~V})$ to $0.94 \mathrm{pF}(6$ $\mathrm{V})$. Both frequency tunability and polarization reconfigurability are controlled in the antenna utilizing the proposed fell branch line coupler feed network. The four single post twofold toss and two dual in-line bundle switches are utilized in the feed network to control the tunable impedance bandwidth of the antenna over a wideband from 1.25 to 2.95 $\mathrm{GHz}$.

H. T. Chattha et al.,[3] A frequency reconfigurable printed microstrip-sustained fix antenna is proposed here. The antenna comprises of a microstrip feed associated with a roundabout emanating component isolated into three patches which are associated through silicon PIN diodes utilized as switches for accomplishing reconfigurability as being shabby and simple to actualize having high switching capacities.

Amjad Iqbal et al.,[4] In this work, a minimized reconfigurable monopole antenna is proposed working at three distinct frequencies relying on the state of the optical switch. The proposed reconfigurable antenna in the territory of ON switch has thunderous frequencies of $2.45 \mathrm{GHz}$ and $5.4 \mathrm{GHz}$ covering the band of $1.8-2.7 \mathrm{GHz}(\mathrm{Wi}-\mathrm{Fi}$ ) and 5.26-5.99 GHz (WLAN) separately. A similar antenna during OFF condition of switch works just at $3 \mathrm{GHz}$ covering the band of $2.49-3.84 \mathrm{GHz}$. The proposed multiband reconfigurable antenna is planned and created on a FR-4 substrate having relative permittivity of 4.4, misfortune digression of 0.02 and thickness of $1.6 \mathrm{~mm}$.

The antenna is fit for the frequency trading at various frequency between $2 \mathrm{GHz}$ to $6 \mathrm{GHz}$. The results are practiced unmistakable frequencies, gain, bandwidth, directivity.

The impact of openings with a solitary PIN diode is contemplated and recreation results were dissected. For PIN diode ON condition the structured reconfigurable antenna is reverberating at $2.2 \mathrm{GHz}, 5.4 \mathrm{GHz}$ and for OFF condition it is resounding at $3 \mathrm{GHz}$. The executed antenna can be utilized for L-band, S-band and C-band wireless applications[4].

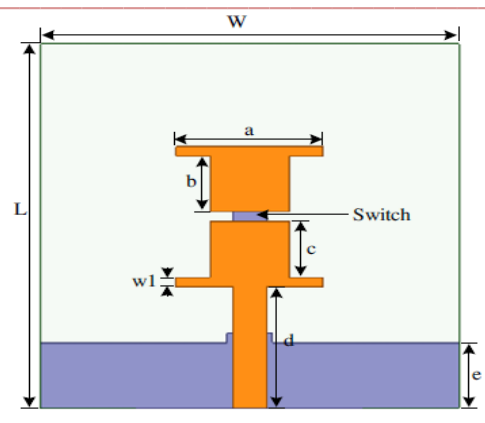

Figure 2: Reconfigurable Antenna[4]

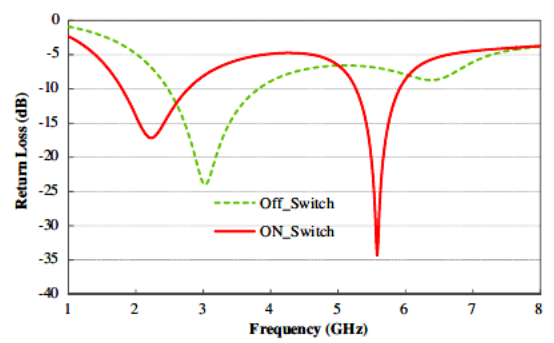

Figure 3: Return loss vs Frequency[4]

P. F. Hu et al.,[5] A wideband separating patch antenna is researched in this paper. The fix antenna is encouraged by a Fformed test, which comprises of one upper and two lower flat arms, just as a vertical arm that interfaces them. Attributable to the novel excitation plot, two test modes alongside a fix mode are at the same time energized inside the passband, creating a wide bandwidth of $21.3 \%$ with stable antenna increases and radiation patterns. In the interim, cross-coupling is built in the antenna, creating two symmetrical radiation nulls directly at the different sides of the passband. Thus, a smaller separating antenna with bandpass reaction and high selectivity is gotten, without using any additional sifting circuit.

Y. Qian et al.,[5] An epic single-feed microstrip antenna with polarization deftness is proposed. Stacking the refined water cylinder(s) at the four corners of the square fix with various statures, the powerful permittivity of thunderous mode is changed. By annoying the statures of the four water chambers, the roundabout polarization radiation with a wide $3-\mathrm{dB}$ hub proportion beamwidth can be gotten.

Table 1: Summery of Literature Survey

\begin{tabular}{|c|c|c|c|}
\hline $\begin{array}{c}\text { Sr } \\
\text { No. }\end{array}$ & $\begin{array}{c}\text { Author } \\
\text { Name \& } \\
\text { year }\end{array}$ & $\begin{array}{c}\text { Proposed } \\
\text { Work }\end{array}$ & Outcome \\
\hline 1 & $\begin{array}{c}\text { Bilal Ijaz, } \\
2018\end{array}$ & $\begin{array}{c}\text { Dual-Band } \\
\text { Monopole } \\
\text { Antenna }\end{array}$ & $\begin{array}{c}\text { Resonant frequency } \\
3.66 \mathrm{GHz} \text { and } 4.56 \mathrm{GHz}\end{array}$ \\
\hline 2 & $\begin{array}{c}\text { S. } \\
\text { Kumar,2018 }\end{array}$ & $\begin{array}{c}\text { polarisation } \\
\text { reconfigurabl } \\
\text { e antenna }\end{array}$ & $\begin{array}{c}\text { Impedance bandwidth } \\
\text { of } 2.09-2.96 \mathrm{GHz}\end{array}$ \\
\hline 3 & $\begin{array}{c}\text { Amjad } \\
\text { Iqbal, 2017 }\end{array}$ & $\begin{array}{c}\text { compact } \\
\text { reconfigurabl } \\
\text { e monopole } \\
\text { antenna }\end{array}$ & $\begin{array}{c}\text { On- } 2.45 \mathrm{GHz} \text { and } \\
\text { Off- } 2.49-3.84 \mathrm{GHz}\end{array}$ \\
\hline 4 & $\begin{array}{c}\text { A. } \\
\text { circularly } \\
\text { polarized } \\
\text { antenna }\end{array}$ & $\begin{array}{c}1 \text {-dB AR beamwidth of } \\
\text { up to } 83^{\circ} .\end{array}$ \\
\hline 5 & $\begin{array}{c}\text { J. A. A. } \\
\text { Byford,2015 }\end{array}$ & $\begin{array}{c}\text { Frequency } \\
\text { reconfigurabl } \\
\text { e antenna }\end{array}$ & $\begin{array}{c}2 \mathrm{X} 2 \text { array and } \\
\text { reduction of the } \\
\text { resonance frequency }\end{array}$ \\
\hline
\end{tabular}




\section{TYPES OF ANTENNA RECONFIGURATION}

Reconfigurable antennas can be ordered by the antenna parameter that is powerfully balanced, commonly the frequency of activity, radiation pattern or polarization.

\section{i. Frequency reconfiguration}

Frequency reconfigurable antennas can change their frequency of activity progressively. They are especially helpful in circumstances where a few correspondences frameworks merge on the grounds that the numerous antennas required can be supplanted by a solitary reconfigurable antenna. Frequency reconfiguration is for the most part accomplished by physical or electrical alterations to the antenna measurements utilizing RF-switches, impedance stacking or reasonable materials.

\section{ii Radiation pattern reconfiguration}

Radiation pattern reconfigurability depends on the purposeful alteration of the circular dispersion of the radiation pattern. Bar guiding is the most expanded application and comprises of controlling the course of greatest radiation to augment the antenna gain in a connection with cell phones. Pattern reconfigurable antennas are typically planned utilizing mobile/rotatable structures or switchable and responsively stacked parasitic components. Over the most recent 10 years, metamaterial-based reconfigurable antennas have picked up consideration due their little structure factor, wide pillar controlling reach and wireless applications.

\section{iii Polarization reconfiguration}

Polarization reconfigurable antennas are equipped for switching between various polarization modes. The ability of switching between flat, vertical and roundabout polarizations can be utilized to decrease polarization jumble misfortunes in compact gadgets. Polarization reconfigurability can be given by changing the harmony between the various methods of a multimode structure.

\section{iv Compound reconfiguration}

Compound reconfiguration is the ability of at the same time tuning a few antenna parameters, for example frequency and radiation pattern. The most widely recognized application of compound reconfiguration is the blend of frequency deftness and shaft examining to give improved ghastly efficiencies. Compound reconfigurability is accomplished by joining in a similar structure distinctive single-parameter reconfiguration systems or by reshaping powerfully a pixel surface.

\section{v. Switching Components \& Application}

PIN Diodes - fundamental switching components used to change the RF current stream in the circuit. It has the preferences that ease, simple to manufacture, quick switching reaction, and dependable. PIN diode has just a single disadvantage that it has high DC predisposition current. A point by point discourse about different configurability and overview of different reconfigurable antennas are talked about in the up and coming areas of the paper.

Varactor Diodes - it has the preferred position that the present move through varactor diode is little when contrasted with PIN diode. The disadvantage is that varactor diodes are nonlinear and low powerful range.

MEMs - it has a more prominent favorable position that low power misfortune and inclusion misfortune. The downside is that moderate switching speed and has complex creation.

Applications-

- Pattern Reconfigurable Antenna for MIMO System

- Reconfigurable monopole antennas for WLANIWIMAX application

- Frequency Reconfigurable Antenna for a Cognitive Radio Application

- Reconfigurable Antennas for Satellite Applications

\section{CONCLUSION}

Distinctive reconfigurable antennas are utilized in different wireless applications, for example, subjective radio, space, satellite correspondence and portable radio and so on. Reconfigurable antennas are more effective than all other antenna strategies since single antenna can be worked with various modes. It is reasonable for single antenna with multiuse applications or clients to utilize. It furnishes progressively proficient correspondence with least expense. The attributes and arrangements of reconfigurable antenna have been exhibited in this paper. As another idea of antenna, reconfigurable antenna appreciates extraordinary worth and great prospects. For structuring and reproducing of reconfigurable antenna, CST Microwave Studio (CST MWS)2018 device can be utilized.

\section{REFERENCE}

[1]. B. Ijaz, A. Iftikhar, K. S. Alimgeer, M. S. Khan and R. Shubair, "A Frequency Reconfigurable Dual-Band Monopole Antenna for Wireless Applications," 2018 International Symposium on Networks, Computers and Communications (ISNCC), Rome, 2018, pp. 1-5.

[2]. S. Kumar M and Y. Kumar Choukiker, "Tunable wideband frequency and switching polarisation reconfiguration antenna for wireless applications," in IET Microwaves, Antennas \& Propagation, vol. 12, no. 15, pp. 2364-2371, 19122018.

[3]. H. T. Chattha, N. Aftab, M. Akram, N. Sheriff, Y. Huang and Q. H. Abbasi, "Frequency reconfigurable patch antenna with bias tee for wireless LAN applications," in IET Microwaves, Antennas \& Propagation, vol. 12, no. 14, pp. 2248-2254, 2811 2018.

[4]. Amjad Iqbal, Omar A. Saraereh" A Compact Frequency Reconfigurable Monopole Antenna for Wi-Fi/WLAN Applications" Progress In Electromagnetics Research Letters, Vol. 68, 79-84, 2017

[5]. Y. Qian and Q. Chu, "A Polarization-Reconfigurable WaterLoaded Microstrip Antenna," in IEEE Antennas and Wireless Propagation Letters, vol. 16, pp. 2179-2182, 2017.

[6]. N. Nguyen-Trong, A. Piotrowski and C. Fumeaux, "A Frequency-Reconfigurable Dual-Band Low-Profile Monopolar Antenna," in IEEE Transactions on Antennas and Propagation, vol. 65, no. 7, pp. 3336-3343, July 2017.

[7]. A. Narbudowicz, M. J. Ammann and D. Heberling, "Reconfigurable Axial Ratio in Compact GNSS Antennas," 
in IEEE Transactions on Antennas and Propagation, vol. 64, no. 10 , pp. 4530-4533, Oct. 2016.

[8]. M. Soltanpour and M. M. Fakharian, "Compact filtering slot antenna with frequency agility for Wi-Fi/LTE mobile applications," in Electronics Letters, vol. 52, no. 7, pp. 491-492, 142016.

[9]. J. A. Byford, K. Y. Park, P. Chahal and E. J. Rothwell, "Frequency reconfigurable patch antenna array," in Electronics Letters, vol. 51, no. 21, pp. 1628-1630, 8102015.
[10].N. Nguyen-Trong, L. Hall and C. Fumeaux, "A Frequency- and Polarization-Reconfigurable Stub-Loaded Microstrip Patch Antenna," in IEEE Transactions on Antennas and Propagation, vol. 63, no. 11, pp. 5235-5240, Nov. 2015. 